\title{
Both sides now: diagnostic imaging medical physics in two hemispheres
}

\author{
Donald McRobbie $e^{1,2,3,4}$
}

Published online: 8 June 2017

(C) Australasian College of Physical Scientists and Engineers in Medicine 2017

\section{A personal journey}

It is an immense privilege and a significant professional experience to have worked in medical physics on two sides of the globe and within two diverse healthcare systems. It has been an interesting journey, although occasionally feeling like bumping down the medical physics equivalent of a dirt track, to have had opportunity to shape the diagnostic imaging medical physics service for the whole of South Australia and to participate in professional activities nationally through ACPSEM, RANZCR, ARPANSA and the TGA.

After a successful career spanning both academic and hospital sectors in the UK, I moved to Adelaide to be the Chief (and only!) Medical Physicist for just one hospital, Flinders Medical Centre. In London, I was the Director of the Radiological Sciences Unit of Imperial College Healthcare NHS Trust and Imperial College London (the University), responsible for diagnostic imaging medical physics and radiation safety (including MRI) for pretty much the whole of North West London (population $2 \mathrm{M}$ ). At Flinders in Southern Adelaide I was looking to get back to the "shop floor" to do some hands-on medical physics.

So what are the differences between Australasian and British medical physics? Firstly the terminology: we didn't

Donald McRobbie

donald.mcrobbie@adelaide.edu.au

1 SA Medical Imaging Physics, SA Health, Adelaide, Australia

2 Flinders Medical Centre, Adelaide, Australia

3 School of Physical Sciences, University of Adelaide, Adelaide, Australia

4 Department of Surgery, Imperial College, London, UK have DIMPs and ROMPs. More significantly, our workforce had expertise and responsibility for the whole of the electro-magnetic spectrum, with some individuals possessing their primary expertise in non-ionising radiations, ultrasound and MRI. We also had compulsory state registration and a government run training scheme (Modernising Scientific Careers). Not all of these things were ideal.

\section{On every street corner}

On moving here in late 2013, I noticed several things. Firstly, there seemed to be a radiology clinic on every street corner. Why do we need so many? The answer came during my first week of work whilst preparing a radiation safety talk for my new department: to satisfy the huge demand from GPs and clinicians for imaging. A comparison of figures released by the respective national radiation regulators show that the average public radiation burden from medical exposures is 4 times greater in Australia than in the UK [1, 2]. As an anecdotal example, a local GP wanted to refer me for imaging even before I underwent the routine blood test which could (and did) rule out any need for imaging. Why? Also on entering this GP surgery, patients were greeted with the sign "we only keep your X-ray films for 12 months before disposal." Triple why! What about the integrity and longevity of patient records? What about the requirement to use previous imaging if available? And, in the digital age, what's this film thing? Welcome to Australia.

Another difference is that whilst the UK's average dose from diagnostic radiation has only increased by $30 \%$ in the last two decades, Australia's has doubled. If we believe in the LNT model (and, notwithstanding a recent editorial in this journal, we should-indeed we must from a legislative perspective), Australia's rate of cancer induction 
arising from diagnostic imaging is comparable to the UK's in absolute terms, with a projected 2000 fatal cancers from medical diagnostic radiation per year, making up 3\% of the total cancer incidence. If you then do a correlation with (a) the number, and (b) the influence achieved by, and respect given to-DIMPs working in radiology, you'll see the scope of the problem. The recent ARPANSA online education resources on justification of diagnostic imaging procedures [3] are timely and important. There is always a riskbenefit consideration in radiology, but over or unnecessary examination only adds risk.

\section{Linear no threshold or hormesis no action}

On a scientific note, whilst acknowledging the important implications of low dose (hormesis) research, the evidence of radiation effects on humans is exclusively on the harmful side. It is ionising radiation. It causes physical damage. There is nothing more undermining to good radiation safety practice than the belief or suspicion "that it might be good for us after all." Whilst there is debate about the methodological detail, recent papers using a Big Data approach show for the first time a causal dose response relationship between radiation received from $\mathrm{CT}$ scans by children and cancer incidence $[4,5]$. The findings of 50-60 mGy tripling leukaemia and brain cancer risk, and $4.5 \mathrm{mSv}$ resulting in a $24 \%$ increase in cancer and leukaemia incidence brings known deleterious effects into diagnostic imaging territory. Subsequent studies have refined but not contradicted these conclusions $[6,7]$. Similar conclusions emerge from the INWORKS study on occupationally exposed workers [8]. Radon in the home or down mines provides the other low dose situation where a causality has consistently been shown between exposures of a few milli-sieverts per year and lung cancer [9]. Doses of a few milli-sieverts therefore matter, and so do the activities of justification, optimisation and limitation - and the role of medical physicists in diagnostic imaging.

\section{Professional strengths and weaknesses}

I attended my first EPSM conference in Sydney in November 2016 and was delighted to meet many of my peers, both from the DIMP and ROMP camps. I was impressed with the range and quality of work presented-in the more service-orientated areas such as DRLs, eye dose, skin doseand also in blue-sky research areas, particularly around the MR-Linac.

It has also been encouraging to be involved with the TEAP scheme. I am impressed with the depth of the training offered. It far exceeds the level of the current UK programme. The requirement for registrars to publish is important, as medical physicists need to have the analytical, reflective and communication skills that publishing their work entails.

These are strengths. What are our weaknesses? Firstly, operating in a federal system, with devolved legislation (the UK has devolved government too, but not for radiation safety) means that issues in one state or territory may not be shared across our meagre workforce (another weakness). Also and obviously is the geography. There isn't another DIMP/ROMP department down the road for me to chat to about common issues. I also believe that the lack of a nationally legislated registration scheme, with protected titles, is a significant weakness, and its establishment should remain a high priority for the College.

\section{Professional threats}

That leads me to the threats to our profession, and here I'm talking about the DIMP side. The damage caused by poorly trained external (non-ARPAB, non-ACPSEM) radiation consultants can be huge. I have witnessed the work of such "experts", who have demonstrated little or no understanding of e.g., modern diagnostic imaging technology, or of modern healthcare delivery. Experts who deny the very real, and published phenomenon of "tertiary scatter" [10-13], using outdated paradigms for shielding design, resulting in unnecessary doses to staff and the public potentially in excess of legal limits. This is a real and serious issue, from Work Health and Safety, public health, regulatory and possible litigation perspectives. The College must stand firm against such practitioners. We must build into our healthcare intitutions' policies that only ACPSEM or ARPAB certified/registered medical physicists have the final say on all radiation room designs. I could cite instances of insufficient or no lead in the walls of CT rooms, or normal glass being used for control room windows, or lead not extending to a sufficient height. There are numerous examples of the insufficiency of radiation protective personal protective equipment on the market- non-lead aprons which do not offer sufficient protection $[14,15]$, or equipment manufacturers offering dubious exposure parameter advice [16], or equipment purchasing decisions being made without adequate scientific input. This is why DIMPs are important. We must work harder to convince our health managers and clinical colleagues that mere "compliance with local regulations" is not sufficient, but that the ARPANSA Codes, RANZCR, ANZSNM, ACPSEM standards (and relevant international ones) must be met by all diagnostic imaging services at all times. We must convince our colleagues to trust and value our expertise. Legal minimum is not best practice. Patients deserve better. 


\section{MRI: an open door?}

I'll finish on the theme of opportunity. Australia and New Zealand have very strong scientific track records for MRI research in institutions such as the Centre for Advanced Imaging and the Herston Imaging Research Facility in Brisbane, the University of Sydney, the Florey Institute in Melbourne, and the Centre for Advanced MRI in Auckland, to name but a few. Many important developments have and are occurring here: high field (7T) MRI, PET-MR, Constrained Spherical Deconvolution tractography with track density imaging, and the MR-Linac. Where are the DIMPs and the ROMPs in these developments? We should be translating these technologies into clinical practice. This is our big opportunity, but it will become a weakness if we remain on the periphery of these exciting advances.

We need to develop our members' expertise in MR safety. Here the paradigm has changed fundamentally: from "what you must not scan" to "what you can scan and under what conditions" with regard to both passive and active implants. The three professionals model of MR safety is rapidly gaining worldwide acceptance: the MR Medical Director, the MR Safety Officer, and the MR Safety Expert. The Institute of Physics and Engineering in Medicine has published guidance on the knowledge and skills of the MR Safety Expert (MRSE) [17] as a professional (usually a medical engineer or physicist) capable of determining the potential risks from implants and exposures from first principles. A MRSE fully understands the underlying physics, the technology, the nature of the tissue (and device) interactions, the clinical applications, and can quantify the riskjust like we do in radiation physics. We should be stepping into this role. In the USA, the independently-constituted American Board of MR Safety has also adopted the three professionals model.

I have been asked by some younger colleagues, how do we get involved with MRI? It's a slow process of gaining confidence, becoming fluently conversant with clinical MRI (i.e. knowing and understanding the pulse sequences which are relevant to clinical users), and winning respect and trust. Helping with quantitative metrics is a good starting point, as is translational research or service development. At Flinders, our clinical head was very keen to implement the Constrained Spherical Deconvolution method of tractography, pioneered in Melbourne [18-20]. This had not been done before in a public hospital setting, and presents many issues of optimising the MR acquisition, the post processing, ensuring quality and the deployment of other clinical science skills that are second nature to medical physicists. Initial results have been promising [21, 22] and the experience rates as one of the most satisfying so far in my career, and has genuinely changed patients' lives. One of my long term goals is to see the development of MR physics expertise and education within the public health sector.

I'm grateful to the Editors for the opportunity to write this piece, and to all my colleagues for their support and inspiration.

\section{References}

1. Oatway WB, Jones AL, Holmes S, Watson S and Cabianca T (2016) Ionising radiation exposure of the UK population: 2010 Review, (Public Health England: Chilton) PHE-CRCE-026

2. ARPANSA (2015) Ionising Radiation and Health factsheet. http://www.arpansa.gov.au/pubs/factsheets/IonisingRadiationandHealth.pdf

3. ARPANSA Radiation Protection of the Patient online module http://www.arpansa.gov.au/rpop/module/index.html\#welcome

4. Pearce MS, Salottie JA, Little MP et al (2012) Radiation exposure from CT scans in childhood and subsequent risk of leukaemia and brain tumours: a retrospective cohort study. Lancet 2012:499-505

5. Matthews JD, Forsythe V, Brady Z et al (2013) Cancer risk in 680000 people exposed to computed tomography scans in childhood or adolescence: data linkage study of 11 million Australians. Br Med J 346:f2360

6. Berrington de Gonzalez A, Salotti J, McHugh K et al (2016) Relationship between paediatric CT scans and subsequent risk of leukaemia and brain tumours: assessment of the impact of underlying conditions. Br J Cancer 114(4):388-394

7. Meulepas JM, Ronckers CM, Merks J et al (2016) Confounding of the association between radiation exposure from CT scans and risk of leukemia and brain tumors by cancer susceptibility syndromes. J Radiol Prot 36(4):953-974

8. Leuraud K, Richardson DB, Cardis E, Robert D et al (2015) Ionising radiation and risk of death from leukaemia and lymphoma in radiation-monitored workers (INWORKS): an international cohort study. Lancet Haematol 2(7):e276-e281

9. Darby S, Hill D, Auvinen A et al (2004) Radon in homes and risk of lung cancer: collaborative analysis of individual data from 13 Euoprean case-control studies. BMJ 330:223-228

10. McRobbie DW (1997) Radiation shielding for spiral CT scanners. Br J Radiol 70:226

11. Fog LS, Cormack J (2010) Mathematical modelling of the radiation dose received from photons passing over and through shielding walls in a PET/CT suite. Health Phys 99:769-779

12. Sutton DG, Martin CJ, Sutton DG, Peet DJ (2012). Radiation shielding for diagnostic radiology, 2nd edn. British Institute of Radiology, London

13. Martin CJ, Sutton DG, Magee J, McVey S, Williams JR, Peet D (2012) Derivation of factors for estimating the scatter of diagnostic X-rays from walls and ceiling slabs. J Radiol Prot 32:373-396

14. Muir S, McLeod R, Dove R (2005) Light-weight lead apronslight on weight, protection or labelling accuracy. Australas Phys Eng Sci Med 28:128-130

15. McRobbie D, Matyagin Y (2014) Lead ambivalence of radiation protection apparel: when is bad good? RANZCR, AIR, ACPSEM Combined Scientific Meeting: Imaging and Radiation in Personalised Medicine, 4-7 Sept. Melbourne, Australia

16. Matyagin YV, McRobbie DW (2016) Muscle and bone dose from low $\mathrm{kVp}$ paediatric digital radiographs. EPSM2016, ACPSEM Annual Conference, Sydney 6-10 Nov 2016. Australas Phys Eng Sci Med 39(4):1158

17. Institute of Physics and Engineering in Medicine (2013) POLICY STATEMENT: Scientific Safety Advice 
to Magnetic Resonance Imaging Units that Undertake Human Imaging. https://www.ipem.ac.uk/Portals/0/Documents/Publications/Policy\%20Statements/ IPEM_MRSafetyExpert_PolicyStatement_04102013_SK.pdf

18. Tournier JD, Calamante F, Gadian DG, Connelly A (2004) Direct estimation of the fiber orientation density function from diffusion-weighted MRI data using spherical deconvolution. Neuroimage 23:1176-1185

19. Tournier JD, Mori S, Leemans A (2011) Diffusion tensor imaging and beyond. Magn Reson Med 65:1532-1556

20. Tournier JD, Calamante F, Connelly A (2012) MRtrix: diffusion tractography in crossing fire regions. Int J Imaging Syst Technol 22:53-66

21. McRobbie DW, Agzarian M (2016) Quality control measures for constrained spherical deconvolution MR diffusion tractography in clinical use. Proceedings of ISMRM 24th Annual Scientific Meeting \& Exhibition vol 24, Toronto

22. McRobbie DW, Agzarian M (2016) Setting up a clinical MR tractography service: initial results and observations. EPSM2016, ACPSEM Annual Conference, Sydney 6-10 Nov 2016. Australas Phys Eng Sci Med 39(4):1072

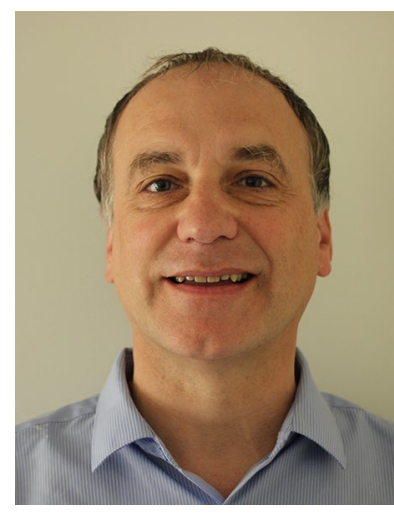

Donald McRobbie is Acting Head of South Australian Medical Imaging Physics, Adjunct Associate Professor at the University of Adelaide, and honorary Senior Lecturer, Department of Surgery, Imperial College London. He is a coauthor of the popular MR physics textbook MRI from Picture to Proton. He was awarded a Distinguished Talent Visa by the Australian Department Immigration and Border Protection in May 2014 for his profestions to medical physics and MRI. 